\title{
A Study on Electroless Deposition of Nickel on Nano Alumina Powder Under Different Sensitization Conditions
}

\author{
D. Sameer Kumar ${ }^{1 *}$, K. N. S. Suman ${ }^{2}$ and P. Rohini Kumar ${ }^{3}$ \\ ${ }^{I}$ Department of Mechanical Engineering, R.V.R. \& J.C. College of Engineering, \\ Guntur, India \\ ${ }^{2}$ Department of Mechanical Engineering, Andhra University College of \\ Engineering, Visakhapatnam, India \\ ${ }^{3}$ Department of Chemical Engineering, R.V.R. \& J.C. College of Engineering, \\ Guntur, India \\ *Corresponding author: me2meer@gmail.com
}

\begin{abstract}
This paper deals with the preparation and characterization of Nickel-coated Alumina ceramic particles by Electroless Plating Technique. Nanosized $\alpha-\mathrm{Al}_{2} \mathrm{O}_{3}$ powders of about $50 \mathrm{~nm}$ in diameter are used for plating. The bath for Electroless Nickel Plating is prepared with $\mathrm{NiCl}_{2} .6 \mathrm{H}_{2} \mathrm{O}, \mathrm{C}_{6} \mathrm{H}_{5} \mathrm{NaO}_{7} . \mathrm{H}_{2} \mathrm{O}, \mathrm{NH}_{4} \mathrm{Cl}$ and $\mathrm{NaH}_{2} \mathrm{PO}_{2} . \mathrm{H}_{2} \mathrm{O}$. A bath temperature of $85^{\circ} \mathrm{C}$, pH value of 8 and stirring time of 20 min is considered to carry out the deposition. The influence of sensitization and activation under different rinsing conditions on the Nickel coating over the Surface of Nano Alumina is studied. The results of these powders are analyzed through morphology, microstructure and phase with scanning electron microscopy (SEM), transmission electron microscopy (TEM) and X-ray diffractometry $(X R D)$ respectively.
\end{abstract}

Keywords: Electroless Plating, Ni deposition, Alumina, Sensitization

\section{Introduction}

Alumina ceramics are widely used as reinforcement in many applications of modern metal matrix composite materials [1]. However, engineering applications of a ceramic material are determined by its brittleness. The composite preparation also suffers from low wettability because of liquid metal and ceramic interactions. As the bonding between metal and ceramic plays a prominent role in deciding the characteristic of the composite, the research is focused at the methods of improving wettability. One such method is modifying the particulate-reinforcement surface using a metal coating as layer [2].

Nickel, known for its excellent corrosion and wear resistance, is a good choice for a coating material. A few methods like co-precipitation method, sol-gel method are employed to prepare the coated powder [3]. On the other hand, the electroless plating method is another option with an advantage in high deposition rate, simple operation and capability of mass production [4]. Another advantage of using electroless nickel is its ability to produce the deposits with a very high degree of uniformity of thickness [5, 9]. The Ni deposit has a good wettability and is generally hard [14].

The Electroless plating proposed by Brenner and Riddell has been widely used during the past two decades in many applications. The plating process consists of two steps. One is surface treatment and the other one is bathing for Plating. The plating through electroless method depends on many process parameters like sensitizing and activating conditions, plating time, $\mathrm{pH}$, Temperature, Stirring, elements and concentration of the bath $[4,5,6,7,9,15]$. So, the conditions must be good enough 
for effective plating. The wrong selection or wrong implementation of process parameter leads to improper or no coating on the particles [6].

Leon et al., [2] reported the electroless nickel deposition with varying sizes at micro level on Sic and $\mathrm{Al}_{2} \mathrm{O}_{3}$ powders and observed uniform and continuous nickel films on both the particles using acidic bath conditions. The Nickel coating on coarse particles by electroless plating method was very well reported but the research on coating of Ultra fine particles was limited [4]. The nano sized ceramic powders have been recognized as effective strengthening second phases for MMCs [7, 8]. The successful electroless deposition of metals on these ultra fine powders is still an issue to address.

The present work confers to the preparation of Ni plating on nano sized $\alpha-\mathrm{Al}_{2} \mathrm{O}_{3}$ powders by standard electroless plating procedures. The influence of sensitization conditions on plating is discussed for the better understanding of mechanisms in the deposition of $\mathrm{Ni}$ on Nano sized $\alpha-\mathrm{Al}_{2} \mathrm{O}_{3}$ particles. Section 2 discusses the Experimental conditions while the other sections are aimed at the results and conclusions.

\section{Experimental}

\subsection{Raw Materials:}

$99 \%$ pure $\alpha-\mathrm{Al}_{2} \mathrm{O}_{3}$ powders of average particle size $50 \mathrm{~nm}$, supplied by $\mathrm{M} / \mathrm{s}$ United Nano Tech Products Limited (UNTPL), Howrah, are used in the present experiment. The primary characteristics of the powder are shown in Table 1.

Table 1. Characteristics of the $\mathrm{Al}_{2} \mathrm{O}_{3}$ Powders used in the Experiment

\begin{tabular}{|l|l|}
\hline Crystallanity & $\alpha-\mathrm{Al}_{2} \mathrm{O}_{3}$ \\
\hline Particle Size & $50 \mathrm{~nm}$ (Avg. Size) \\
\hline Purity & $99 \%$ \\
\hline Density & $3.9 \mathrm{~g} / \mathrm{cm}^{3}$ \\
\hline Crystal Structure & $\mathrm{FCC}$ \\
\hline Appearance & White Solid \\
\hline Melting Point & $\sim 2000^{\circ} \mathrm{c}$ \\
\hline
\end{tabular}

\subsection{Mechanism of Plating:}

The basic principle of Electroless plating is similar to Electro Plating but without many Electrical Contacts and apparatus. Charge transfer takes place through a chemical reduction process. The Electroless plating depends upon the catalytic reduction of a metallic ion in an aqueous solution containing a reducing agent and the subsequent deposition of the metal without the use of electrical energy [9]. In this experiment, Nickel Chloride Hexahydrate $\left(\mathrm{NiCl}_{2} \cdot 6 \mathrm{H}_{2} \mathrm{O}\right)$ is used as a source of Nickel ions while Sodium hypophosphite $\left(\mathrm{NaH}_{2} \mathrm{PO}_{2} \cdot \mathrm{H}_{2} \mathrm{O}\right)$ is the reducing agent. The pre treatment of the powder (Sensitization and Activation) makes the conditions favorable for plating. The nickel deposition with $\mathrm{SnCl}_{2}$ sensitization and $\mathrm{PdCl}_{2}$ activation is employed in the present work [2, 4]. In the sensitization process, $\mathrm{Sn}^{2+}$ ions are absorbed on the surface of the $\mathrm{Al}_{2} \mathrm{O}_{3}$ powders, which could facilitate attracting of $\mathrm{Pd}^{2+}$ ions onto the surface of particles (Eq. 1). When the activated $\alpha-\mathrm{Al}_{2} \mathrm{O}_{3}$ powders are added to the bath, the metallic nickel could be deposited with the following reactions (Eq. 2 \& Eq. 3) taking place [4, 6]. 


$$
\begin{aligned}
& \mathrm{Sn}^{2+}+\mathrm{Pd}^{2+} \longrightarrow \mathrm{Sn}^{4+}+\mathrm{Pd}^{0} \\
& \mathrm{Ni}^{2+}+2 \mathrm{H}_{2} \mathrm{PO}_{2}^{-}+2 \mathrm{H}_{2} \mathrm{O} \longrightarrow \mathrm{Ni}^{0}+2 \mathrm{H}_{2} \mathrm{PO}_{3}{ }^{-}+2 \mathrm{H}^{+}+\mathrm{H}_{2} \\
& \mathrm{Pd}+\mathrm{Ni}^{2+} \longrightarrow \mathrm{Pd}^{2+}+\mathrm{Ni}
\end{aligned}
$$

The $\mathrm{Ni}^{2+}$ ions will be reduced to metallic nickel and the metallic $\mathrm{Pd}^{0}$ oxidized to $\mathrm{Pd}^{2+}$. That is, both oxidation and reduction reactions happen in the process. Pang et.al [4] has given an illustration of mechanism in the plating process of ultrafine particles (Figure 1).

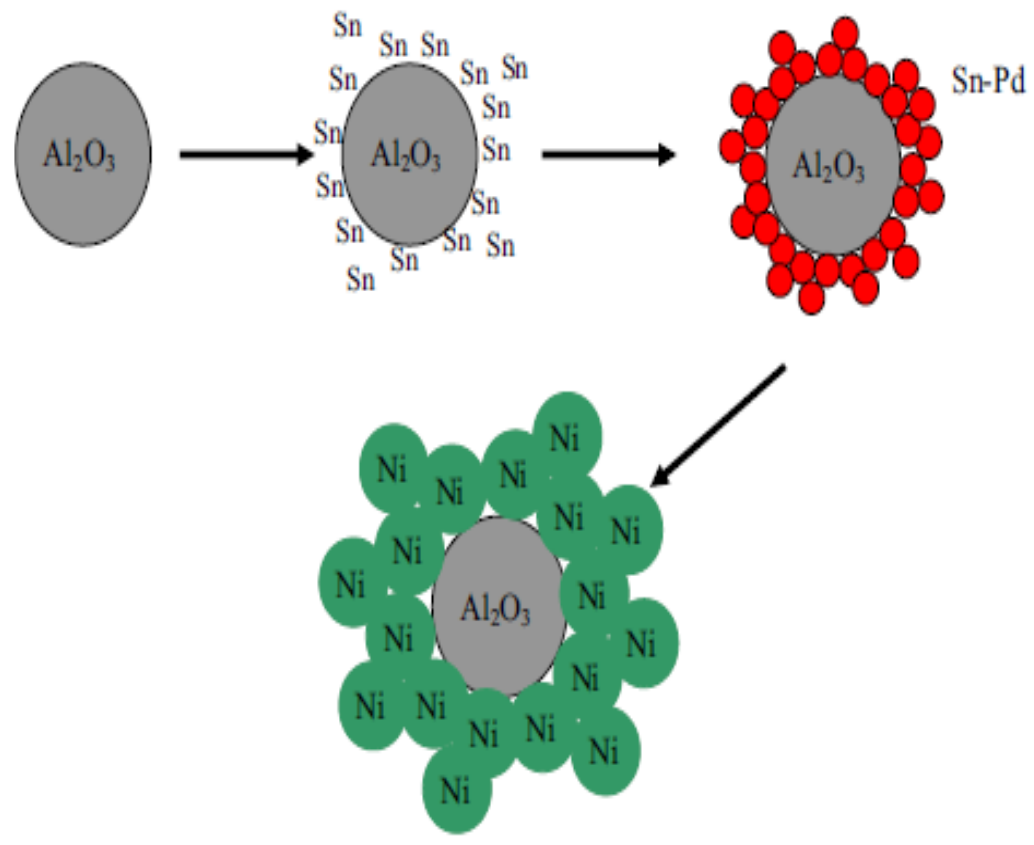

\section{Figure 1. The Schematic Diagram Indicating the Ni Plating Process with $\mathrm{SnCl}_{2}$ Sensitization and $\mathrm{PdCl}_{2}$ Activation [4]}

\subsection{Experimental Procedure:}

As mentioned in the earlier section, the plating process involves two steps, Viz. Pretreatment (Surface preparation) and Bathing. Initially, the powder was treated with acetone using Ultrasonic cleaner and later on with different chemicals to complete the pretreatment process. $\mathrm{Xu}$ et al., reported Ultrasonic agitation promotes better nucleation and deposition of nickel than mechanical agitation in case of nickel-coated graphite [10]. The detailed description of the chemicals and their purposes used for experimentation are mentioned in the Table 2 . The powders are rinsed with distilled water and are dried in each step.

The pretreated powder is sent to the electroless nickel deposition bath. The alkaline solution bath was adapted for the advantage of having low phosphorous content [11, 12]. The bath elements used here are less in quantity and have an economical advantage than those proposed by pang et al., [4]. The deposition bath for plating was prepared using the formulations given in the literature [13] and is indicated in Table 3. 
Table 2. Pre-treatment Process

\begin{tabular}{|c|c|c|c|c|}
\hline \multicolumn{5}{|c|}{ Pre Treatment Process } \\
\hline Process & Chemicals & Concentration & Time & Purpose \\
\hline $\begin{array}{l}\text { Ultra Sonic } \\
\text { Cleaning }\end{array}$ & Acetone & & $20 \mathrm{Min}$ & $\begin{array}{l}\text { Removes Volatile } \\
\text { compounds from the } \\
\text { surface and makes the } \\
\text { particle surface clean }\end{array}$ \\
\hline Etching & $\mathrm{HNO}_{3}$ & $10 \mathrm{ml} / \mathrm{L}$ & $15 \mathrm{Min}$ & $\begin{array}{l}\text { Microscopic } \\
\text { Roughening }\end{array}$ \\
\hline Rinsing & $\begin{array}{l}\text { Distilled } \\
\text { Water }\end{array}$ & & $5 \mathrm{Min}$ & \\
\hline Sensitization & $\begin{array}{l}\mathrm{SnCl}_{2 .} 6 \mathrm{H}_{2} \mathrm{O} \\
+ \\
\mathrm{HCl} \\
\end{array}$ & $\begin{array}{l}10 \mathrm{~g} / \mathrm{L} \\
30 \mathrm{ml} / \mathrm{L}\end{array}$ & $15 \mathrm{Min}$ & $\begin{array}{l}\text { Breaks the surface } \\
\text { integrity and makes } \\
\text { ready for activation }\end{array}$ \\
\hline Rinsing & $\begin{array}{l}\text { Distilled } \\
\text { Water }\end{array}$ & & $5 \mathrm{Min}$ & \\
\hline Activation & $\begin{array}{l}\mathrm{PdCl}_{2}+ \\
\mathrm{HCl}\end{array}$ & $\begin{array}{l}0.25 \mathrm{~g} / \mathrm{L} \\
3 \mathrm{ml} / \mathrm{L}\end{array}$ & $15 \mathrm{Min}$ & $\begin{array}{l}\text { Activate the pores and } \\
\text { prepare the surface for } \\
\text { plating }\end{array}$ \\
\hline Rinsing & $\begin{array}{l}\text { Distilled } \\
\text { Water }\end{array}$ & & 5 Min & \\
\hline
\end{tabular}

Table 3. Composition and Conditions of the Bath

\begin{tabular}{|l|c|}
\hline \multicolumn{1}{|c|}{ Chemicals and Conditions } & Concentration \\
\hline Nickel chloride, hexahydrate $\left(\mathrm{NiCl}_{2} \cdot 6 \mathrm{H}_{2} \mathrm{O}\right)$ & $30 \mathrm{~g} / \mathrm{L}$ \\
\hline Sodium hypophosphite Mono Hydrate $\left(\mathrm{NaH}_{2} \mathrm{PO}_{2} \cdot \mathrm{H}_{2} \mathrm{O}\right)$ & $25 \mathrm{~g} / \mathrm{L}$ \\
\hline Ammonium Chloride $\left(\mathrm{NH}_{4} \mathrm{Cl}\right)$ & $50 \mathrm{~g} / \mathrm{L}$ \\
\hline Tri Sodium Citrate $\left(\mathrm{Na}_{3} \mathrm{C}_{6} \mathrm{H}_{5} \mathrm{O}_{7} \cdot 2 \mathrm{H}_{2} \mathrm{O}\right)$ & $40 \mathrm{~g} / \mathrm{L}$ \\
\hline Sodium Hydroxide $(\mathrm{NaOH})$ & To maintain the required $\mathrm{pH}$ \\
\hline Bath Temperature & $85 \pm 2^{0} \mathrm{C}$ \\
\hline pH & 8 \\
\hline Time & $20 \mathrm{Min}$ \\
\hline
\end{tabular}

Table 4. Sensitization and Activation Conditions

\begin{tabular}{|c|c|}
\hline $\begin{array}{l}\text { Samples } \\
\text { Designation }\end{array}$ & Condition \\
\hline A & Pure $\alpha-\mathrm{Al}_{2} \mathrm{O}_{3}$ powder \\
\hline B & $\begin{array}{c}\mathrm{SnCl}_{2} \begin{array}{c}\text { sensitization and rinsed in water for Five times with } \\
\text { subsequent } \mathrm{PdCl}_{2} \text { Activation }\end{array}\end{array}$ \\
\hline $\mathrm{C}$ & $\begin{array}{c}\mathrm{SnCl}_{2} \text { sensitization and rinsed in water for Three times with } \\
\text { subsequent } \mathrm{PdCl}_{2} \text { Activation }\end{array}$ \\
\hline D & $\begin{array}{l}\mathrm{SnCl}_{2} \text { sensitization and rinsed in water for One time with subsequent } \\
\qquad \mathrm{PdCl}_{2} \text { Activation }\end{array}$ \\
\hline
\end{tabular}


So as to study the significance of sensitization on electroless nickel plating, $\mathrm{Al}_{2} \mathrm{O}_{3}$ powder after immersion in $\mathrm{SnCl}_{2}$ solution, was rinsed for one, three and five times with distilled water followed by dried in each step. The detailed conditions used in the experiment along with sample designations are given in Table 4.

\subsection{Characterization of Powders:}

The surface morphology of the $\alpha-\mathrm{Al}_{2} \mathrm{O}_{3}$ powders before and after electroless $\mathrm{Ni}$ deposition was characterized. The characterization was done with the support of FE Scanning Electron Microscope (SIGMA HV - Carl Zeiss With Bruker Quantax 200 - Z10 EDS Detector) equipped with an energy dispersive spectroscopy (EDS). The Transmission Electron Microscope (TEM, JEOL/JEM 2100) and the crystallographic characteristics of $\mathrm{Ni}$ were analyzed by X-ray powder diffractometer (Bruker AXS D8) at Sophisticated Test $\&$ Instrumentation Centre, CUSAT Campus, Cochin, INDIA.

\section{Results and Discussion}

From the literature, the reduction of nickel is always accompanied by the evolution of hydrogen gas [6]. The reaction of hypophosphite (Eq. 2) is the main reason. When the Samples B, C and D were added to the bath for plating at the conditions specified, the hydrogen gas was evolved in Samples C and D (Figure $2 b$ ) and liberation was very poor in the Sample B (Figure 2a). The color change may justify the presence of Nickel in Samples $\mathrm{C}$ and $\mathrm{D}$.

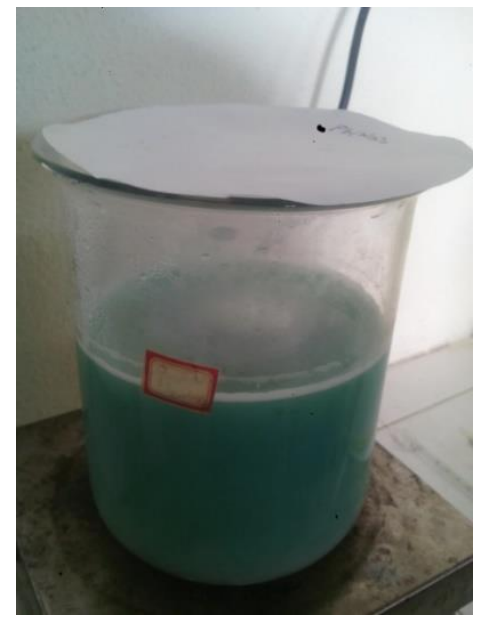

(a) Sample B

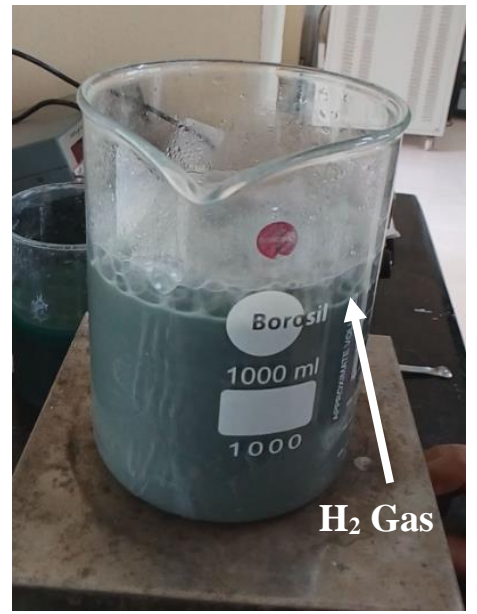

(b) Sample D

Figure 2. Evolution of Hydrogen Gas during Plating Process

The photographs of Sample A, B, C and D after plating were shown in Figure 3. The color of the powders was darker in sequence. The color of Sample A is white, while the color of Sample C is grey and Sample D is black. The Sample B does not show any major color change and it is in greenish white. The darker the color the rich in deposition of $\mathrm{Ni}$ [4]. These results indicated the possible signs of good Ni deposition in Sample D. The reason for less color change in Sample $\mathrm{B}$ may be due to the absorbed $\mathrm{Sn}^{+2}$ ions on the surface of $\mathrm{Al}_{2} \mathrm{O}_{3}$ particles during sensitization process being rinsed out because of washing more times [4]. So it does not acquire enough strength to attract nickel from the bath.

The density was measured using Archmedian principle. The average of five readings was calculated and observed. The density of Sample A (pure $\alpha-\mathrm{Al}_{2} \mathrm{O}_{3}$ ) is 3.90 $\mathrm{g} / \mathrm{cm}^{3}$ while the densities of Sample B,C and D are $3.96 \mathrm{~g} / \mathrm{cm}^{3}, 4.03 \mathrm{~g} / \mathrm{cm}^{3}$ and 4.15 $\mathrm{g} / \mathrm{cm}^{3}$ respectively. Sample D has superior density compared to the remaining 
Samples. The increase in density of samples may be due to the addition of metallic $\mathrm{Ni}$ on the surface of Alumina ceramic. Leon et.al., [2] also observed the increased density values in the experiment conducted with micro particles. On correlating the results of Hydrogen gas liberation, Color change and density values of all the samples, Sample B is neglected from further discussion as it does not shown any potential results in the initial tests. The results presented in the later parts of the section focus on the effectiveness of plating in Samples C and D in accordance with preliminary confirmations.

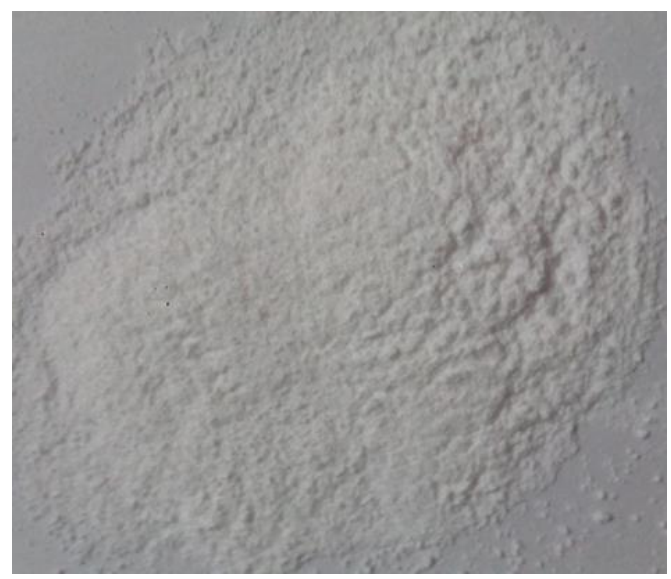

(a) Sample A

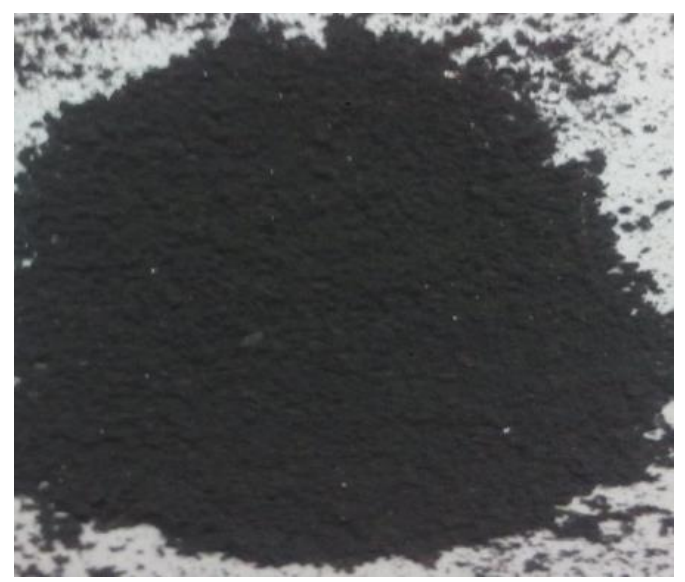

(c) Sample C

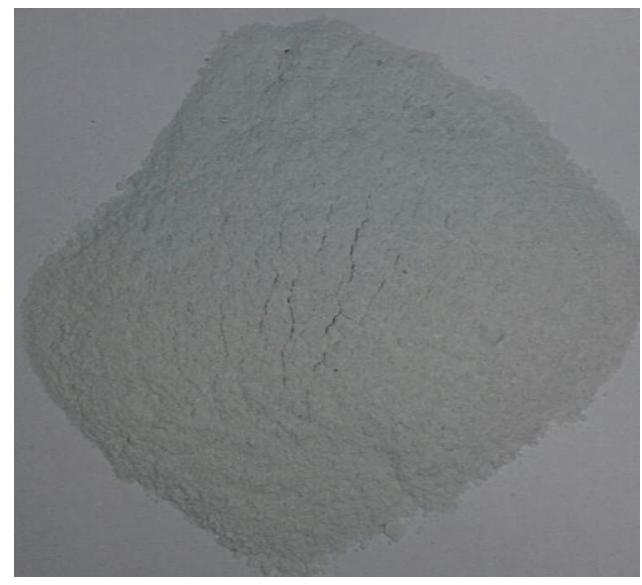

(b) Sample B

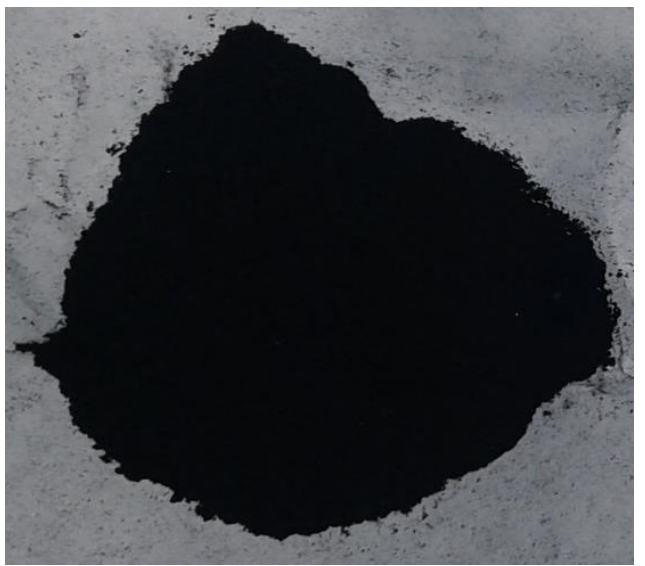

(d) Sample D

Figure 3. Optical Photographs of Raw and Electroless Ni Deposited Powders under Different Conditions

The XRD patterns of powders are shown in Figure 4. Figure 4(a) has the diffraction peaks of $\alpha-\mathrm{Al}_{2} \mathrm{O}_{3}$ (Sample A) while Figure 4(b \& c) contains the diffraction peaks of $\mathrm{Ni}$ coated $\alpha-\mathrm{Al}_{2} \mathrm{O}_{3}$ (Sample $\mathrm{C}$ and D). It was observed that the diffraction peaks in Sample $\mathrm{C}$ and $\mathrm{D}$ were broad when compared with Sample A. A shoulder indicating Ni was obtained at an angle of 44 to the alumina peak in case of sample C. This may be an indication of Metallic nickel added to the surface of Alumina. In particular, the diffraction peaks at 2Theta angle 40-50 were broad in Sample D [Figure 4 (c)] than sample C indicating the more $\mathrm{Ni}$ deposition on the surface of $\alpha-\mathrm{Al}_{2} \mathrm{O}_{3}$ powders [4]. It means that the more rinsing times lead to lower Ni deposition in Sample C. The traces of sharp peaks in the spectrum are the indication of crystalline structure. 


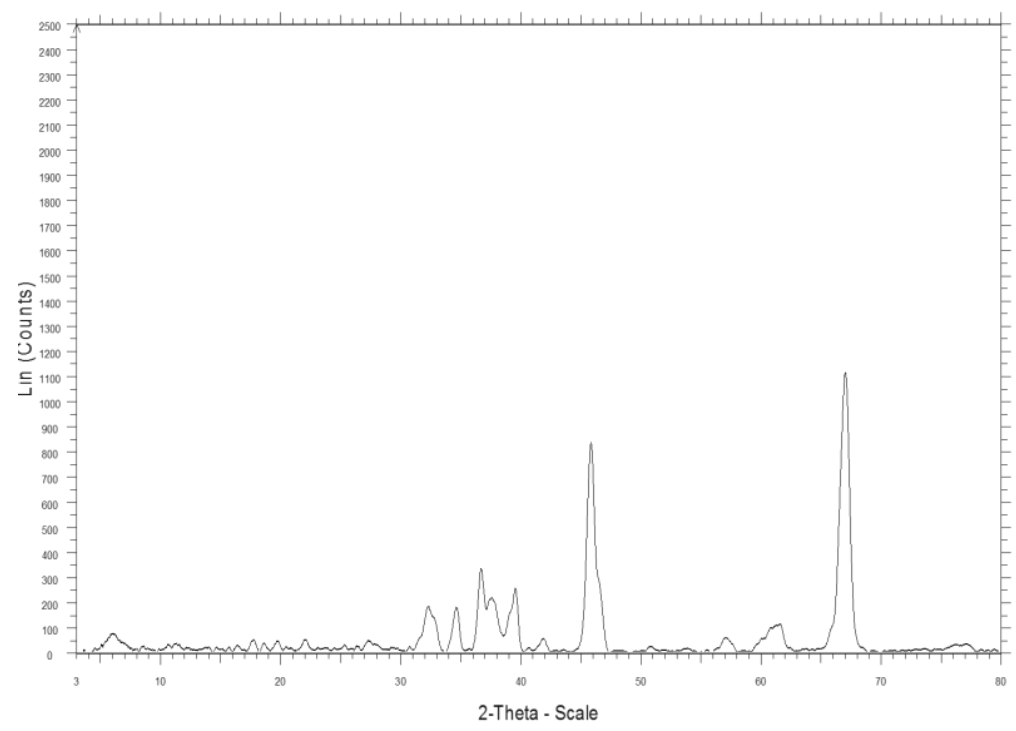

(a)

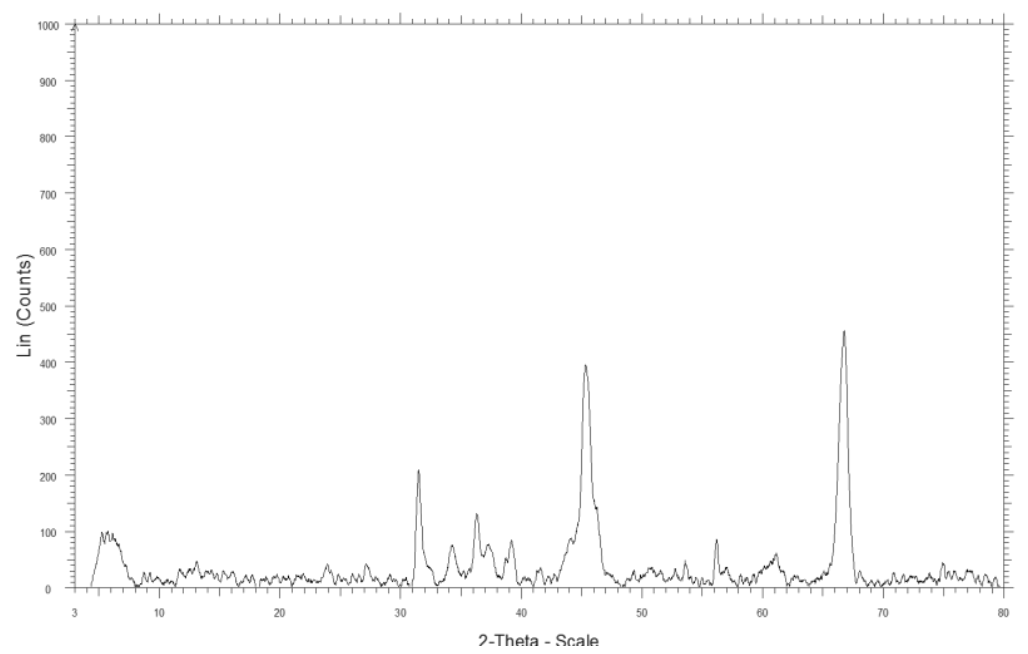

(b)

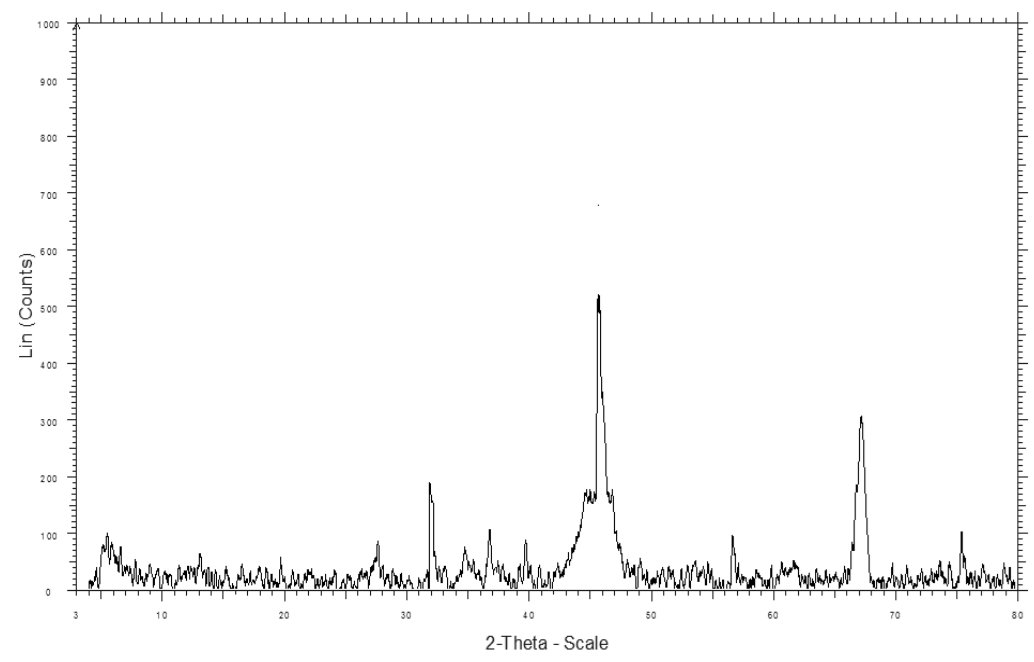

(c)

Figure 4. XRD Data of (a) Sample A (b) Sample C (c) Sample D 
Figure 5 shows the FESEM photographs of nano sized $\alpha-\mathrm{Al}_{2} \mathrm{O}_{3}$ powders before and after electroless deposition. It can be clearly observed that the surfaces of raw powders were smooth and plain [Figure 5(a)]. After electroless nickel deposition, nickel particles were adhered onto the surface of nano sized $\mathrm{Al}_{2} \mathrm{O}_{3}$ particles [Figure 5 (b, c and d)]. This may be the reason for variations of peaks in XRD analysis. It means that the more rinsing times lead to lower Ni deposition in Sample C. The surface of samples D are coated with large amount of nickel. Uniform coating was achieved in case of Sample D [Figure. 5(c)]. The EDS Spectra also confirms the presence of Ni in the Sample D [Figure 6].

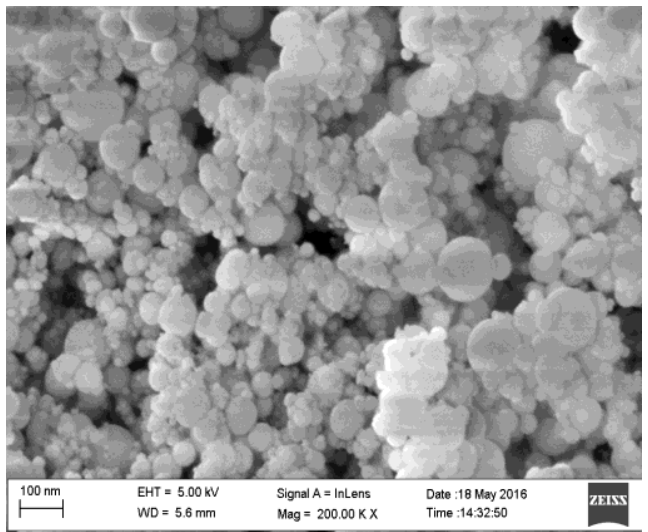

(a) Sample A

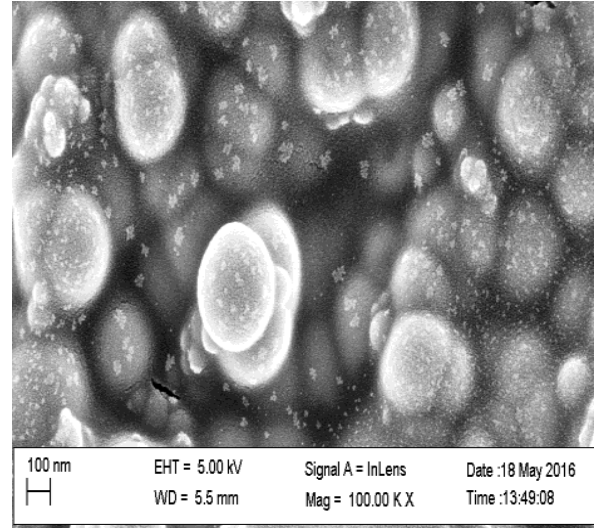

(b) Sample C

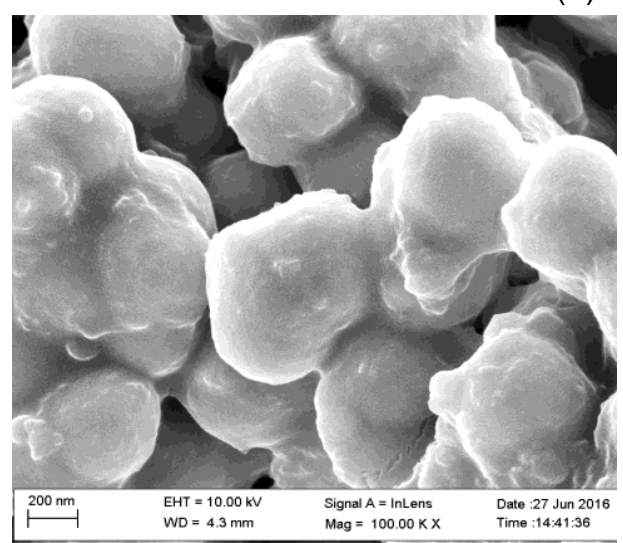

(c) Sample D

Figure 5. FESEM Images of Samples A, C, and D

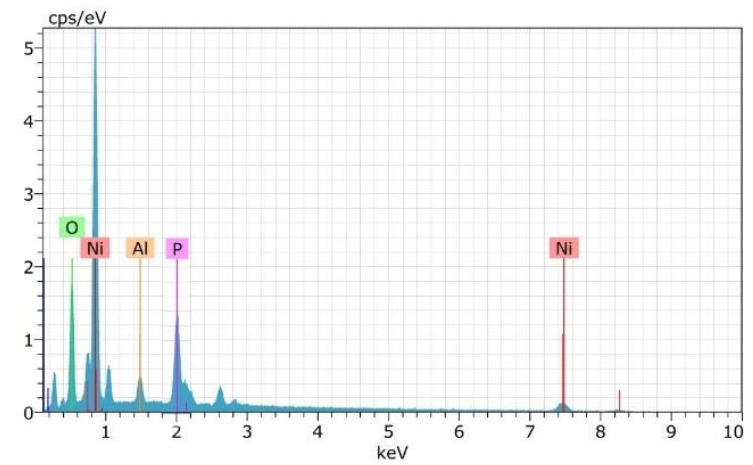

Figure 6. EDS Analysis of Sample D 
The high magnification TEM images to evaluate the phase and coating thickness of powders in case of Samples A, C and D are shown in Fig 7\& 8. The Surfaces of sample C, and $\mathrm{D}$ are not as smooth as sample $\mathrm{A}$ and have shown a clear indication of coating. The surface of sample $\mathrm{C}$ attracted a little amount of $\mathrm{Ni}$. The plating was also not uniform in sample $\mathrm{C}$ as shown in Figure 7(b). The coating thickness was approximately 1-2 $\mathrm{nm}$. The reason for not complete plating was may be due to the $\mathrm{Sn}^{+2}$ ions absorbed during sensitization are partly washed away because of more rinsing times. It could not felicitate good amount of $\mathrm{Pd}^{+2}$ to attract metallic nickel [4]. The maximum coating thickness of $31 \mathrm{~nm}$ was achieved in case of Sample D [Figure 8(a)]. Pang et al., [4] reported a composite like structure rather than a core structure in the experiment conducted with $150 \mathrm{~nm}$ particle using different bath conditions but the experimental conditions considered here resulted a more uniform coating even on 50nm particle size. The Sample D conditions of sensitization and activation provided a good platform for the $\mathrm{Ni}$ deposition over the nano $\mathrm{Al}_{2} \mathrm{O}_{3}$ surface and is confirmed in accordance with XRD and SEM results. The structure of Ni coated Nano $\mathrm{Al}_{2} \mathrm{O}_{3}$ powder was crystalline in case of sample $\mathrm{D}$ when the image observed using SAD which is shown in Figure 8 (b).

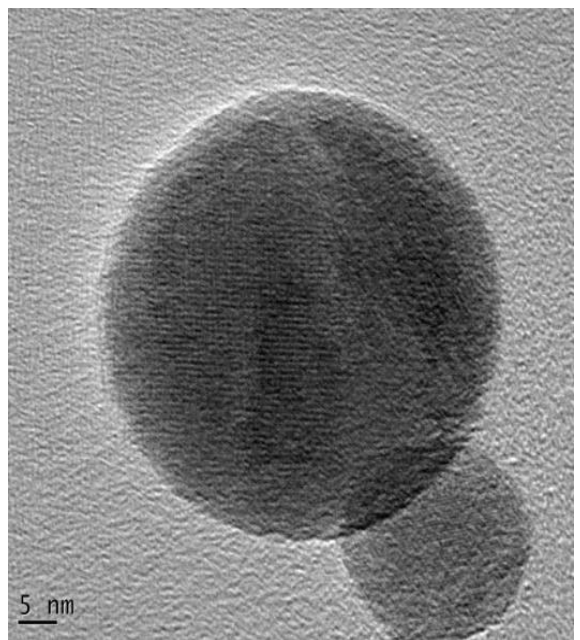

(a) Sample A

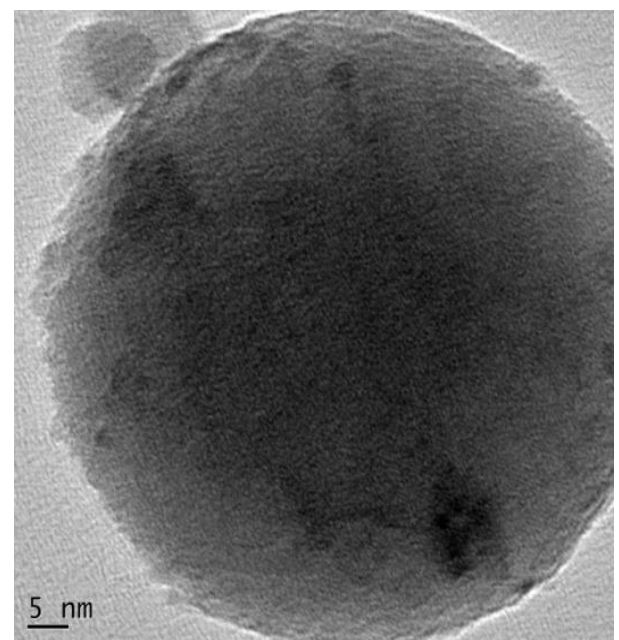

(b) Sample C

Figure 7. TEM Images of Sample A and C

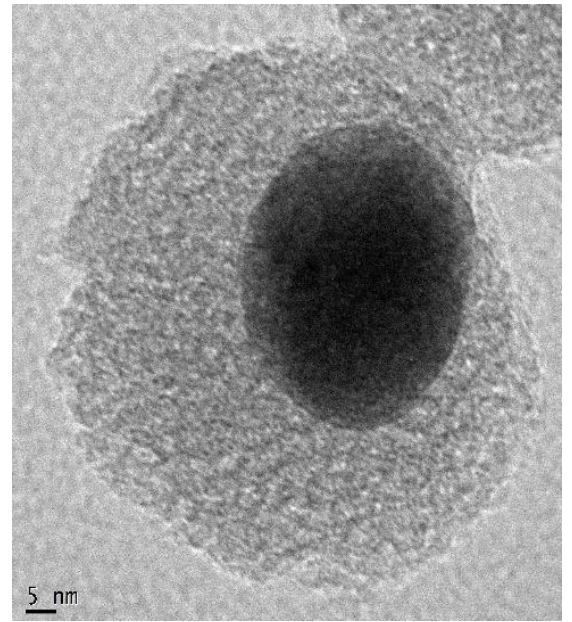

(a) TEM Image

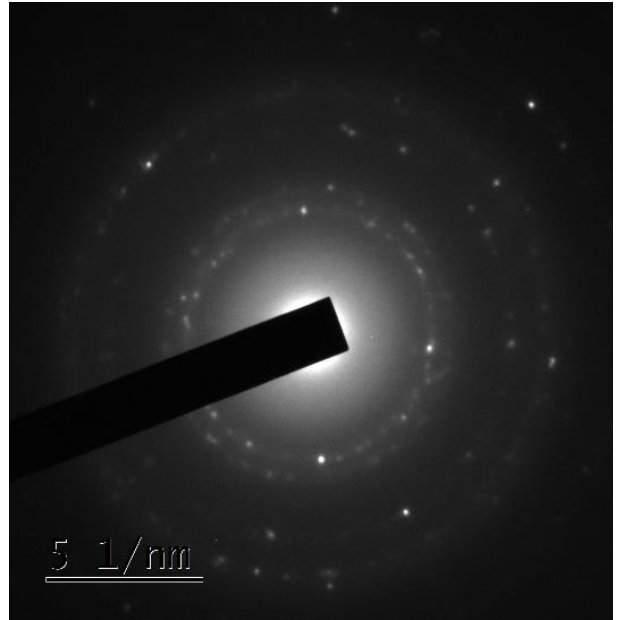

(b) SAD Image

Figure 8. TEM and SAD Images of Sample D 


\section{Conclusions}

The present paper proposes a promising way to reinforce composites with surface modified ceramics for better properties. Nano sized $\mathrm{Al}_{2} \mathrm{O}_{3}$ powders of an average size $50 \mathrm{~nm}$ were successfully and fully coated with Nickel by electroless plating method. The importance of sensitization process in plating was highlighted with more rinsing conditions. More rinsing in sensitization leads to less / no Pd on particle surface and attracted a little amount of nickel for coating. The bath conditions also played a key role in uniform $\mathrm{Ni}$ deposition on the surface of $\mathrm{Al}_{2} \mathrm{O}_{3}$. The color change and density values have given the primary indications and the results of SEM, TEM and XRD, are also convincing and shown the effectiveness of the proposed method for coating on ultrafine ceramic particles.

\section{References}

[1] D. J. Lloyd, "Particle reinforced Aluminium and Magnesium matrix composites", International Materials Reviews, vol. 39, no. 1, (1994), pp. 1-23.

[2] C. A. Leon and R. A. L. Drew, "Preparation of nickel-coated powders as precursors to reinforce MMCs", Journal of Materials Science, vol. 35, (2000), pp. 4763-4768.

[3] G.-j. Li, X.-x. Huang and J.-k. Guo, "Fabrication of Ni-coated Al2O3 powders by the heterogeneous precipitation method", Materials Research Bulletin, vol. 36, (2001), pp. 1307-1315.

[4] J. N. Pang, "Significance of sensitization process in electroless deposition of Ni on nano sized Al2O3 powders”, Ceramics International, http://dx.doi.org/10.1016/j.ceramint.2015.11.137, (2015).

[5] R. Parkinson, "Properties and applications of electroless nickel", Nickel Development Institute. Information from; https://www.nickelinstitute.org/en/TechnicalLiterature/Technical\%20Series/ PropertiesandApplicationsofElectrolessNickel_10081_.aspx

[6] G. O. Mallory and J. B. Hajdu, "Electroless Plating: Fundamentals and Applications", Sponsored and published by American Electroplaters and Surface Finishers Society, Reprint Edition.

[7] C. T. J. Low, R. G. A. Wills and F. C. Walsh, "Electro deposition of composite coatings containing nano particles in a metal deposit”, Surf. Coat. Technol., vol. 201, (2006), pp. 371-383.

[8] M. Paramsothy, J. Chan, R. Kwok and M. Gupta, "A12O3 Nano particle Addition to Commercial Magnesium Alloys: Multiple Beneficial Effects", Nano materials, doi:10.3390/nano2020147, vol. 2, (2012), pp. 147-162.

[9] K. Hari Krishnan, “An Overall Aspect of Electroless Ni-P Depositions- A Review Article”, Metallurgical and Materials Transactions A, vol. 37A, (2006) June, pp. 1917-1926.

[10] X. Xu, Z. D. Cui, S. L. Zhu, Y. Q. Liang, X. J. Yang, "Preparation of nickel-coated graphite by electroless plating under mechanical or ultrasonic agitation", Surf. Coat. Technol., doi:10.1016/j.surfcoat.2013.12.070, vol. 240, (2014), pp. 425-431.

[11] M. Schlesinger, "Electroless Deposition of Nickel", Modern Electroplating, Edited by Mordechay Schlesinger and Milan Paunovic, Fifth Edition, John Wiley \& Sons, Inc., (2010).

[12] X.-C. Wang, W.-B. Cai, W.-J. Wang, H.-T. Liu and Z.-Z. Yu, "Effects of ligands on electroless Ni-P alloy plating from alkaline citrate-ammonia solution", Surface and Coatings Technology, vol. 168, (2003), pp. 300-306.

[13] C. Subramanian and K. Palaniradja, "Effect of Surfactant on the Electroless Ni-P/Ni-B Duplex Coatings on Aluminium 7075", International Journal of Metallurgical Engineering, DOI: 10.5923/j.ijmee.20150402.01, vol. 4, no. 2, (2015), pp. 25-32.

[14] C. A. Loto, "Electroless Nickel Plating - A Review", Silicon, DOI 10.1007/s12633-015-9367-7, vol. 8, no. 2, (2016) April, pp. 177-186.

[15] A. Bund, Denny Thiemig, "Influence of bath composition and $\mathrm{pH}$ on the electro codeposition of alumina nano particles and nickel”, Surface \& Coatings Technology, vol. 201, (2007), pp. 7092-7099. 